\title{
Os custos dos acidentes de trânsito envolvendo jovens de 18 a 29 anos de idade em cinco cidades da região oeste do Paraná
}

\author{
The costs of traffic accidents involving young people aged 18 to 29 years in five \\ cities of the western region of Paraná
}

\author{
Diuslene Rodrigues da Silva ${ }^{1}$ \\ Zelimar Soares Bidarra ${ }^{2}$
}

\begin{abstract}
Resumo
Este estudo é parte de uma tese de doutorado e aborda, como discussão central, a problemática da violência no trânsito envolvendo jovens de 18 (dezoito) a 29 (vinte e nove) anos em cinco cidades localizadas na região oeste do Paraná. Trata-se de uma pesquisa descritivo analítica, que utilizou como fonte o Banco de Dados do Corpo de Bombeiros do Paraná (SYSBM-RGO), SIM/DATASUS e SIH/SUS. Foram pesquisados os anos de 2012, 2013 e 2014, com uma amostragem intencional estratificada. Na pesquisa, a referida violência não diz respeito à violência que ocorre no espaço urbano, mas, especificamente, a violência no trânsito, retratada no elevado número anual de mortes e lesionados. Os dados apontam os elevados custos aplicados na política pública de saúde, sinalizando que a redução dos gastos nessa modalidade de atendimento poderia reverter em melhores oportunidades na formação dos jovens.
\end{abstract}

Palavras-chave: Violência. Acidente de trânsito. Juventude. Região oeste do Paraná.

\begin{abstract}
This study is part of a doctoral thesis and addresses, as central discussion point, the problem of traffic violence, involving young people aged 18 (eighteen) to 29 (twenty-nine) years, in five cities located in the Western Region of Paraná. This is an analytical-descriptive research that used as source the Database of the Fire Department of Paraná (SYSBM-RGO), SIM/DATASUS, and SIH/SUS. The years 2012, 2013 and 2014 were searched with a stratified intentional sampling. In the research, the violence referred to does not mean the one that occurs in urban space, but, specifically, the one in traffic, portrayed in the high annual number of deaths and injuries. The data indicate the high costs applied in the public health policy, signaling that the reduction of expenses in this type of care could turn into better opportunities in the training of the young.
\end{abstract}

Keywords: Violence. Traffic accident. Youth. Western region of Paraná.

\footnotetext{
${ }^{1}$ Doutora em Desenvolvimento Regional e Agronegócio (UNIOESTE). Professora da Universidade Estadual do Oeste do Paraná - Campus Toledo. E-mail: diuslene.fabris@ hotmail.com.

${ }^{2}$ Doutora em Educação (UNICAMP). Professora do Programa de Pós-Graduação em Desenvolvimento Regional e Agronegócio (UNIOESTE - Campus Toledo. E-mail: zelimar@yahoo.com.br.
} 


\section{Introdução}

Embora existam muitas diferenças regionais e até mesmo locais, os jovens das cidades médias brasileiras possuem em comum o fato de estarem entre o espaço da ruralidade (o interior) e a urbanidade (das grandes cidades). Para além dessa condição, poucas são as pesquisas que tratam da condição da juventude em cidades de médio porte. Após a questão da violência e da juventude ter deixado de ser restrita às áreas de maior concentração da pobreza, tem crescido a atenção dirigida aos jovens.

A tematização da juventude pela ótica do "problema social" é histórica. Ganha espaços no âmbito social a partir do momento em que representa alguma forma de ameaça à ordem e à continuidade social.

Responsabilizada por todos os anseios de continuidade das gerações vigentes, a juventude é pensada a partir da perspectiva do desenvolvimento social e pessoal de capacidades, ficando sujeita ao critério do ajuste aos papéis adultos, e sempre que o "ajustamento" não ocorre, essa passa a ser vista como um problema ou disfunção.

A propósito, o século XXI conserva a ideia do jovem desajustado, que se constitui em uma ameaça à integridade social. Essa leitura fragmentada da juventude deixa de levar em conta os processos sociais de exclusão e o momento de exacerbação do individualismo, que predomina no âmbito de todas as relações sociais.

$\mathrm{Na}$ especificidade histórica, econômica e social do Brasil pode-se observar que desde a sua fundação, este tem um crescimento e um desenvolvimento acompanhado por práticas violentas, que incidem diretamente, inclusive, nas populações mais jovens (KEIL, 2005).

A tabela a seguir retrata as taxas de mortes violentas no território nacional no ano de 2012 para a faixa etária dos 18 (dezoito) aos 29 (vinte e nove) anos de idade. Os anos de 2013 e 2014 não tiveram os números disponibilizados, sendo que aqui a tabela assume a função ilustrativa do número de ocorrências de mortes violentas. Cabe salientar que a realidade expressa na tabela, em que a morte por homicídios aparece $\mathrm{m}$ primeiro lugar, foi uma tendência confirmada nos anos seguintes, tanto que o documento Mapa da Violência de 2015 traz em destaque os números das mortes por arma de fogo ${ }^{3}$.

\footnotetext{
${ }^{3}$ Disponível em: 〈http://www.mapadaviolencia.org.br/pdf2015/mapaViolencia2015.pdf〉.
} 
TABELA 1 - MORTALIDADE VIOLENTA POR IDADES SIMPLES. BRASIL (2012)

\begin{tabular}{c|c|c|c|c}
\hline \multirow{2}{*}{ Faixa Etária } & \multicolumn{4}{|c}{ TAXAS } \\
\cline { 2 - 5 } & Homicídio \% & Suicídio \% & Transporte \% & Violentas \% \\
\hline 18 & 66,7 & 4,7 & 28,4 & 99,8 \\
19 & 73,0 & 5,8 & 36,6 & 115,3 \\
20 & 76,3 & 5,2 & 37,2 & 118,7 \\
21 & 75,0 & 6,2 & 42,8 & 124,0 \\
22 & 70,2 & 7,1 & 37,1 & 114,3 \\
23 & 73,1 & 7,3 & 37,0 & 117,4 \\
24 & 68,9 & 6,5 & 38,0 & 109,2 \\
25 & 64,3 & 7,5 & 37,4 & 102,6 \\
26 & 61,7 & 7,2 & 33,7 & 98,5 \\
27 & 56,1 & 7,8 & 34,7 & 97,2 \\
28 & 57,5 & 7,7 & 32,0 & 99,1 \\
29 & 57,3 & 7,6 & 34,3 & \\
\hline
\end{tabular}

FONTE: Mapa da Violência 2014.

A tabela não deixa dúvidas acerca do volume de mortes na faixa etária da população jovem. Observa-se que os números começam a apresentar redução de incidência a partir dos 27 (vinte e sete) anos. No entanto, o documento original não apresenta menções conclusivas a esse respeito.

Nessa mesma direção, sinaliza-se a concentração de óbitos e lesões no contingente mais jovem da população, cabendo observar na Tabela 2, a seguir, o número de indenizações pagas pela seguradora oficial do seguro de Danos Pessoais causados por Veículos Automotores de vias Terrestres (DPVAT) às vítimas de acidentes por faixa etária.

TABELA 2 - INDENIZAÇÕES PAGAS POR FAIXA ETÁRIA ${ }^{4}$

\begin{tabular}{lcc}
\hline \multicolumn{1}{c|}{ Faixa Etária } & 2013 & 2014 \\
\hline 65 anos ou mais & 24.930 & 28.486 \\
45 a 64 anos & 116.431 & 144.201 \\
35 a 44 anos & 120.225 & 146.882 \\
25 a 34 anos & 179.816 & 215.744 \\
18 a 24 anos & 154.216 & 182.369 \\
8 a 17 anos & 29.615 & 35.921 \\
0 a 7 anos & 8.612 & 9.762 \\
\hline
\end{tabular}

FONTE: Adaptado de SEGURADORA LÍDER (2015).

Observa-se que o maior número de indenizações se concentra no intervalo etário dos 18 (dezoito) aos 34 (trinta e quatro) anos de idade, totalizando no período de 01 de janeiro de 2013 a 31 de dezembro de 2014 o pagamento de 1.397.21 indenizações.

Na sequência está a tabela geral de indenizações pagas sem o recorte etário:

\footnotetext{
${ }^{4}$ Números absolutos. O Anuário estatístico do DPVAT teve sua primeira edição no ano de 2011, sendo que a cada ano foi sendo melhorado e apresentadas novas informações. O número de indenizações por idade aparece a primeira vez em 2013, por isso não foi possível a apresentação do ano de 2012.
} 
TABELA 3 - INDENIZAÇÕES PAGAS NO PERÍODO DE 2012 A 2014

\begin{tabular}{l|c|c|c|c|c|c}
\hline \multicolumn{1}{c|}{$\begin{array}{c}\text { Natureza da } \\
\text { indenização }\end{array}$} & 2012 & $\%$ & 2013 & $\%$ & 2014 & $\%$ \\
\hline Morte & 60.752 & 12 & 54.767 & 9 & 52.226 & 7 \\
Invalidez permanente & 352.495 & 69 & 444.206 & 70 & 595.693 & 78 \\
$\begin{array}{l}\text { Despesas médicas } \\
\text { (DAMS) }\end{array}$ & 94.668 & 19 & 134.872 & 21 & 115.446 & 15 \\
\hline
\end{tabular}

FONTE: Adaptado de SEGURADORA LÍDER 2012/2013/2014

Os dados da Tabela 3 demonstram que no período pesquisado ocorreu uma significativa redução no número de indenizações por morte, crescendo as despesas médicas, item no qual estão localizados os casos que consideram a invalidez temporária e, também, as indenizações por invalidez permanente.

$\mathrm{Na}$ tabela a seguir estão representados os pagamentos de indenizações por invalidez ocasionados por acidentes com motocicleta. De igual forma, ocorre aqui a concentração nas mesmas faixas etárias, totalizando 474.346 indenizações para o mesmo período. Fica, assim, registrada a magnitude da problemática que representa hoje para o país o uso das motocicletas nas cidades, inclusive como meio de trabalho e não somente de transporte.

TABELA 4 - INDENIZAÇÕES PAGAS POR INVALIDEZ POR ACIDENTES COM MOTOCICLETAS PORFAIXA ETÁRIA ${ }^{5}$

\begin{tabular}{l|c}
\hline Faixa Etária & 2014 \\
\hline 65 anos ou mais & 9.345 \\
45 a 64 anos & 76.512 \\
35 a 44 anos & 92.519 \\
25 a 34 anos & 145.326 \\
18 a 24 anos & 128.010 \\
8 a 17 anos & 18.656 \\
0 a 7 anos & 3.978 \\
\hline
\end{tabular}

FONTE: SEGURADORA LÍDER (2015).

A Tabela 4 retrata o número de indenizações por invalidez em acidentes com motocicleta por faixa etária. Os dados seguem a mesma tendência no que se refere às faixas etárias de maior incidência.

No conjunto, as tabelas apresentadas revelam uma problemática atual e que tem recebido pouca atenção por parte da abordagem das políticas do Estado e no meio acadêmico. O número total de jovens mortos em acidentes com motocicletas, que no período retratado foi de 22.616,

\footnotetext{
5 Destaca-se que o Anuário passou a apresentar dados exclusivos dos acidentes com motocicletas em função destes apresentarem um considerável aumento.
} 
apresenta-se inferior ao número de indenizações por invalidez, que além de significar um elevado custo social no curto prazo, pode comprometer também o desenvolvimento econômico e social de cidades e regiões por cessar ou atrasar os ciclos de inovação.

Diante das questões apresentadas, ilustradas em números, há de se considerar que a violência não é um fenômeno que ocorre à parte da sociedade, das suas relações, da sua produção e reprodução. Ela produz importantes perdas para as cidades, regiões e para o país. Ademais, impacta em condições necessárias para o desenvolvimento econômico e afeta diretamente diferentes indicadores sociais.

Não obstante, suas consequências incidem diretamente sobre o ser humano e seus prejuízos podem ser observados na redução da expectativa de vida, no montante de gastos com saúde, na sensação generalizada de insegurança ou em diversos outros aspectos do bem-estar individual afetado pela violência. No âmbito da economia, a violência tem pelo menos três efeitos importantes, sendo: sobre o denominado capital humano, o capital físico e a composição do produto interno bruto dos países.

No que concerne ao capital humano, a violência o reduz mediante a perda direta de vidas e do impacto da insegurança sobre a produtividade do trabalho. Do ponto de vista do capital físico, a violência, por meio da utilização de recursos - mão de obra e equipamentos para combater o crime afeta o nível e a composição do produto do país e altera a alocação ótima de insumos, através da reorientação do espaço urbano e da inibição de oferta de trabalho. Portanto, a violência não tem custo apenas para a vítima, mas para o conjunto da sociedade.

\section{Metodologia}

Este estudo se caracterizou como uma pesquisa descritivo-analítica, que buscou explicar o contexto de um fenômeno, tendo como ambiente do estudo cinco municípios da região oeste do Paraná de médio e pequeno portes cuja principal atividade econômica se pauta no agronegócio. 


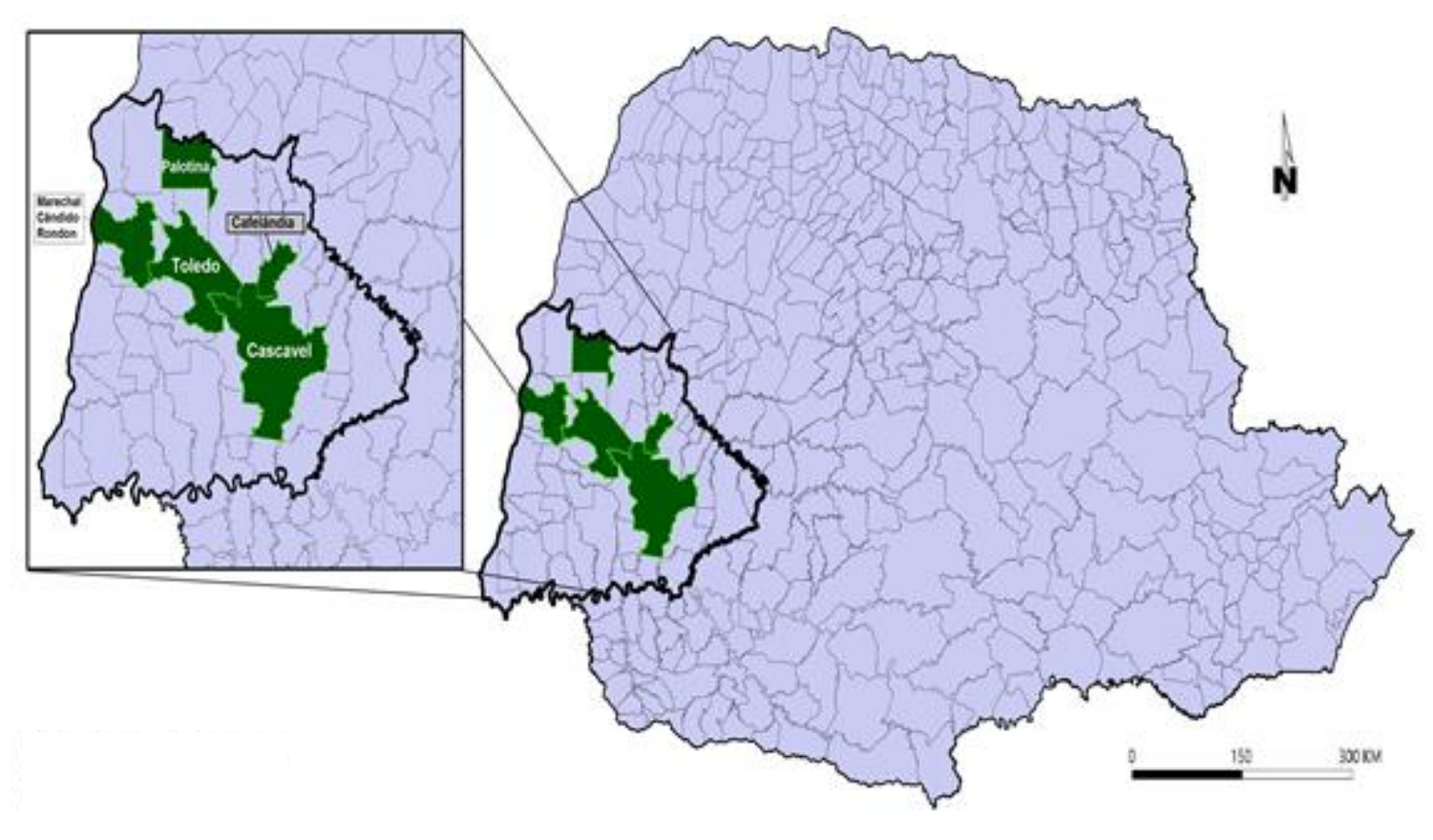

FIGURA 1 - MUNICÍPIOS SELECIONADOS

FONTE: Adaptado de IBGE (2010).

Os cinco municípios eleitos para o estudo apresentam similaridades em suas constituições históricas e atividades econômicas. Segundo dados do Ipardes (2013), nesses municípios os três principais produtos do agronegócio são: galináceos, suínos e bovinos, respectivamente, sendo expressiva também a produção de leite, soja e milho. Contudo, mantêm significativas diferenças com relação ao porte, composição populacional, processos de crescimento e de desenvolvimento. Os cinco municípios compreendem um pequeno espaço, em termos geográficos, no qual estão distribuídos, segundo estimativas do IBGE (2015), 543.133 (quinhentos e quarenta e três mil, cento e trinta e três) habitantes, sendo que, aproximadamente, $32 \%$ desse montante é de população jovem.

Com relação às fontes e ao universo de coleta de dados, estes se deram em documentos, fontes secundárias, de órgãos governamentais, como arquivos da Polícia Militar e Banco de Dados $(\text { SYSBM-RGO })^{6}$ do $4^{\circ}$ Grupamentos de Bombeiros, sediado em Cascavel, o qual mantém nesse banco o registro das ocorrências das cinco cidades pesquisadas.

Também foram coletados dados nos sites oficiais do Departamento de Trânsito do estado (Detran) e do Departamento Nacional de Trânsito (Denatran), nos quais foram capturados os registros das estatísticas anuais de frota, dos acidentes e vítimas. No âmbito da área da saúde, a coleta dos dados ocorreu na sede da $10^{\mathrm{a}}$ Regional de Saúde, localizada na cidade de Cascavel, e na $20^{\mathrm{a}}$ Regional de Saúde, da cidade de Toledo, que alimentam o Banco de Dados da Secretaria de Estado da Saúde

\footnotetext{
${ }^{6} \mathrm{http}: / / \mathrm{www} \cdot$ bombeiroscascavel.com.br/registroccb/imprensa.php
} 
(SESA) nos sistemas SIH-SUS e SIM/DATASUS.

A amostra da pesquisa foi intencional estratificada em 3 (três) grupos: a) por idade de acordo com a proposta de pesquisa; b) vítimas com óbitos; e c) vítimas com lesões. Extraiu-se do número total de registros de acidentes de trânsito ocorridos nas áreas urbanas ${ }^{7}$ dos municípios de Cascavel, Toledo, Palotina, Marechal Cândido Rondon e Cafelândia ${ }^{8}$ para o período de 01 de janeiro de 2012 a 31 de dezembro 2014 as pessoas com idade de 18 (dezoito) a 29 (vinte e nove) anos, na condição de condutor, de passageiro ou de pedestre.

Para a análise de dados, foi utilizada a análise interpretativa descritiva, cujas principais categorias de interpretação partiram do referencial teórico e estão estruturadas levando em conta a localização dos acidentes num ambiente específico: as cidades, suas funções, as questões da mobilidade e do trânsito.

\section{$O$ custo da violência para a sociedade}

Progressivamente, a temática da violência urbana tem ocupado mais espaço no mundo acadêmico e nas mídias de massa. Na especificidade da violência no trânsito, expressa pelo número de acidentes, possui peculiaridades ainda pouco discutidas, como: o impacto econômico que representa para a sociedade e para o Estado, aferido em políticas de trânsito, segurança, saúde e previdência.

Estudos realizados pelo Instituto de Pesquisa Econômica Aplicada (IPEA), com a Associação Nacional de Transportes Públicos (ANTP), com o apoio do Denatran, Ministério da Saúde e Ministério dos Transportes revelaram dados importantes sobre o custo social dos acidentes de trânsito, levando em consideração dados referentes aos anos 2004/2005. Para isso, entenderam que a anatomia de um acidente de trânsito é composta por alguns componentes, como: as pessoas envolvidas, feridas, mortas, pessoas sem ferimento algum e/ou terceiros (pedestre e transeuntes); os veículos - parcial ou totalmente destruídos, com pequenos ou nenhum dano à via e ao ambiente; mobiliário, propriedades públicas ou privadas, clima, iluminação; ao aparato institucional e aos aspectos socioambientais - legislação, fiscalização, administração da via e seu entorno, entre outros

\footnotetext{
${ }^{7}$ Apesar do recorte da pesquisa tratar da área urbana, foram consideradas na coleta de dados as máquinas agrícolas, visto que diante da realidade regional, ocasionalmente, condutores desse tipo de veículo transitam na área urbana e se envolvem em acidentes nas vias ou acessos.

${ }^{8}$ A cidade de Cafelândia tem seus dados apresentados somente para a fonte da $10^{\text {a }}$ Regional de Saúde, Detran e Conatran. Já para a base do $4^{\circ}$ Grupamento de Bombeiros de Cascavel, suas ocorrências estão incorporadas às da cidade de Cascavel.
} 
(IPEA, 2006).

Segundo o referido estudo do Ipea (2006), a partir de tal perspectiva, tornou-se possível averiguar os componentes de cada acidente, permitindo mensurar os custos associados ao atendimento pós-hospitalar; perda de produção; remoção/translado; gasto previdenciário; danos materiais aos veículos; perda de carga; remoção/pátio; reposição; processos judiciais; atendimento policial; danos à propriedade pública e privada. Na primeira versão publicada, o estudo revelou que o custo médio de uma pessoa ilesa é de $\mathrm{R} \$ 1.040,00$; de uma pessoa ferida é de $\mathrm{R} \$ 36.305,00$ e de uma pessoa morta é de R \$270.165,00 (IPEA, 2006, p. 55).

Numa segunda versão apresentada em Brasília em 23 de setembro de 2015, foram expostos os resultados da atualização dos valores e a análise da evolução dos custos dos acidentes de trânsito nas rodovias federais, nos anos-base 2007, 2010 e 2014, bem como uma atualização monetária dos custos dos acidentes nas demais rodovias brasileiras (IPEA, 2015, p. 17; 18; 19; 20).

Esse segundo estudo do Ipea (2015, p. 21) apontou que o custo dos acidentes de trânsito nas rodovias federais cresceu 35\% em relação aos números apresentados entre 2007 e 2014 . Contudo, registrou-se uma leve tendência de queda entre os anos de 2010 e 2014, considerando valores constantes de dezembro de 2014. A quantidade de acidentes subiu cerca de $40 \%$ desde 2007 . No período 2010 a 2014 houve uma inversão dessa tendência. Os principais fatores que contribuíram para a elevação dos custos dos acidentes - número de mortes e acidentes com mortes - também tiveram forte tendência de crescimento (52\% e 37\% respectivamente, entre 2007 e 2014). Contribui com o aumento do custo o aumento de feridos graves, que apresentou crescimento de $21 \%$ entre 2007 e 2014 (IPEA, 2015, p. 22).

O estudo citado evidencia que mesmo com o crescimento da frota de veículos no período comparado, houve uma redução do volume de acidentes e de acidentes graves, o que pode indicar o sucesso de medidas como a concentração das operações da polícia nos trechos críticos e melhorias da infraestrutura e de equipamentos de controle de velocidade. Ainda assim, o estudo chamou a atenção para o fato de que os custos com os acidentes são muito maiores em função do aumento de todos os seus componentes. Inclusive demonstrou a nítida tendência de crescimento da participação dos acidentes com envolvimento de motocicletas (IPEA, 2015).

Segundo o Ipea (2015, p. 20), em média o custo individual de cada acidente foi de $\mathrm{R} \$ 72.705,31$, e quando com vítima fatal o custo foi elevado a cerca de $\mathrm{R} \$ 646.762,94$. Esse tipo de acidente respondeu por menos de $5 \%$ do total de ocorrências, mas representou cerca de $35 \%$ dos custos totais; os automóveis respondem pela maior parte dos custos dos acidentes em função da maior frota circulante nas rodovias. 
Dados da Organização Mundial da Saúde (2009 apud MESQUITA, 2012, p. 152) assinalam que as perdas globais originadas por lesões ocasionadas em acidentes de trânsito são estimadas em 518 bilhões de dólares, custando aos governos entre 1 a 3\% de seus produtos internos brutos. Também são responsáveis por sobrecarga dos serviços de saúde com alta demanda de profissionais de saúde, unidades de terapia intensiva e leitos hospitalares.

Ademais, os acidentes de trânsito apresentam consequências diversas que influenciam a qualidade de vida e as condições de saúde da população. As lesões e adoecimentos podem gerar sequelas, incapacitações, transtornos mentais e comportamentais, dentre outras. Logo, os acidentes correspondem a altos custos dado o grande número de atendimentos e procedimentos em saúde, como consultas, cirurgias, exames de diagnóstico, tratamento e reabilitação. Somam-se a esses custos as aposentadorias precoces, auxílio-doença, entre outros.

Melione e Mello-Jorge (2008, p. 181) mensuraram os gastos diretos do SUS com internações por causas externas em São José dos Campos e relataram que os acidentes de trânsito foram responsáveis por $33 \%$ das internações e a primeira causa nos gastos chegam a $41 \%$ do total das despesas. Soma-se um montante de aproximadamente R $\$ 200$ mil durante o primeiro semestre de 2003.

Um aspecto para se analisar em relação aos acidentes de trânsito diz respeito aos principais fatores de risco: excesso de velocidade, direção sob efeito de bebida alcoólica e outras drogas, ausência de cinto de segurança, ausência ou uso inadequado do capacete, problemas na infraestrutura das rodovias e vias públicas. Importante ter claro que os acidentes e as violências configuram um conjunto de agravos à saúde com grande magnitude e transcendência, provocando forte impacto na morbidade e mortalidade da população.

\section{Os custos em saúde dos acidentes em cinco cidades do oeste paranaense}

Os números apresentados demonstram a magnitude das ocorrências envolvendo jovens, ficando evidente também uma das grandes dificuldades encontrada durante toda a composição desta pesquisa, em todos as suas etapas: trata-se da não sincronicidade dos principais bancos oficiais de dados do país. Ainda assim, a tabela foi organizada com o intuito de dar visibilidade a esse problema. 
TABELA 5 - NÚMERO DE ACIDENTES POR FAIXA ETÁRIA DE 18 A 29 ANOS NO PERÍODO DE 2012 A 2014

\begin{tabular}{l|c|c|c|c|c|c}
\hline \multicolumn{1}{c|}{ Município } & Frota* & População** & $\begin{array}{c}\text { População } \\
\text { jovem** }\end{array}$ & Acidentes* & $\begin{array}{c}\text { Acidentes } \\
\text { com } \\
\text { jovens*** }\end{array}$ & $\begin{array}{c}\% \text { de } \\
\text { acidentes } \\
\text { com jovens }\end{array}$ \\
\hline Cascavel & 201.271 & 286.205 & 64.828 & 7.623 & 5.254 & $68,92 \%$ \\
Toledo & 88.364 & 119.313 & 26.709 & 3.916 & 2.718 & $69,40 \%$ \\
Palotina & 21.414 & 28.683 & 6.001 & 602 & 19 & $18,10 \%$ \\
Marechal C. Rondon & 37.190 & 46.819 & 9.715 & 1.620 & 744 & $45,92 \%$ \\
Cafelândia & 10.028 & 14.662 & 3.250 & 64 & $* * * * * 9$ & $\ldots .$. \\
TOTAL & 358.267 & 495.682 & 110.503 & 13.825 & 8.735 & $63,18 \%$ \\
\hline
\end{tabular}

FONTE: Elaborado pelas autoras. Dados extraídos do anuário estatístico do Detran/PR 2012-2014*; IBGE Censo 2010**; $4^{\circ}$ Grupamento de Bombeiros de Cascavel (SYSBM-RGO)***.

Os resultados apresentados que relacionam os números de população, dos acidentes e de jovens vitimados em acidentes corrobora a importância da temática que trata da crescente participação de jovens em eventos de violência de diversos tipos, especialmente no trânsito. A função social do jovem trabalhador acaba por inseri-lo em mais um espaço das cidades onde se desenrola a violência. Antes, a violência tipicamente atribuída a essa faixa etária se referia à marginalidade e ao uso de substâncias psicoativas. Mas com a inclusão dos jovens no mercado de trabalho, associada ao uso do transporte ágil e barato das motocicletas, eles passaram a ficar mais expostos a um contexto causador de mortes e lesões.

A extensão das lesões e o aumento de dias de internamento preocupam porque prenunciam que o acidentado terá pela frente muitos dias de inatividade e porque, na maioria dos casos, o atendimento para essa recuperação é financiado com dinheiro público. É, provavelmente, esse tipo de recurso que deixou de ser investido em áreas transversais à saúde.

TABELA 5 - INTERNAMENTOS POR SEXO/INVESTIMENTO NOS MUNICÍPIOS PESQUISADOS NO PERÍODO DE 2012 A 2014

\begin{tabular}{l|cc|c|c|c|c}
\hline \multirow{2}{*}{ CIDADE } & \multicolumn{2}{|c|}{ SEXO } & MÉDIA & \multirow{2}{*}{ DIAS DE INTERNAMENTO** } & \multirow{2}{*}{ VALOR } & \multirow{2}{*}{ ÓBITO } \\
\cline { 2 - 4 } & FEM. & MAS. & IDADE* & & & \\
\hline CASCAVEL/CAFELÂNDIA & 15 & 50 & 22 & 378 & $\mathrm{R} \$ 176.480,42$ & 2 \\
TOLEDO & 13 & 33 & 22 & 148 & $\mathrm{R} \$ 101.471,61$ & 3 \\
PALOTINA & 10 & 26 & 22 & 107 & $\mathrm{R} \$ 13.314,53$ & 3 \\
MARECHAL C. RONDOM & 0 & 5 & 25 & 33 & $\mathrm{R} \$ 14.242,95$ & 0 \\
TOTAL & & & & 666 & $\mathrm{R} \$ 305.509,51$ & $8^{* * *}$ \\
\hline
\end{tabular}

FONTE: Elaborado pelas autoras. Dados fornecidos pelas $10^{\mathrm{a}}$ e $20^{\mathrm{a}}$ Regionais de Saúde - SESA/PR (2016).

Os dados apresentados reforçam o aumento da gravidade das lesões, bem como a

\footnotetext{
${ }^{9}$ Como as ocorrências de Cafelândia estão computadas em conjunto com as ocorrências de Cascavel, não foi possível o levantamento desse dado.
} 
prorrogação do tempo para a recuperação. Os registros coletados nas Regionais de Saúde sinalizam os óbitos ocorridos após o atendimento emergencial e durante a internação do paciente, os quais não constam no Banco de Dados do $4^{\circ}$ Grupamento do Corpo de Bombeiros (SYSBM-RGO).

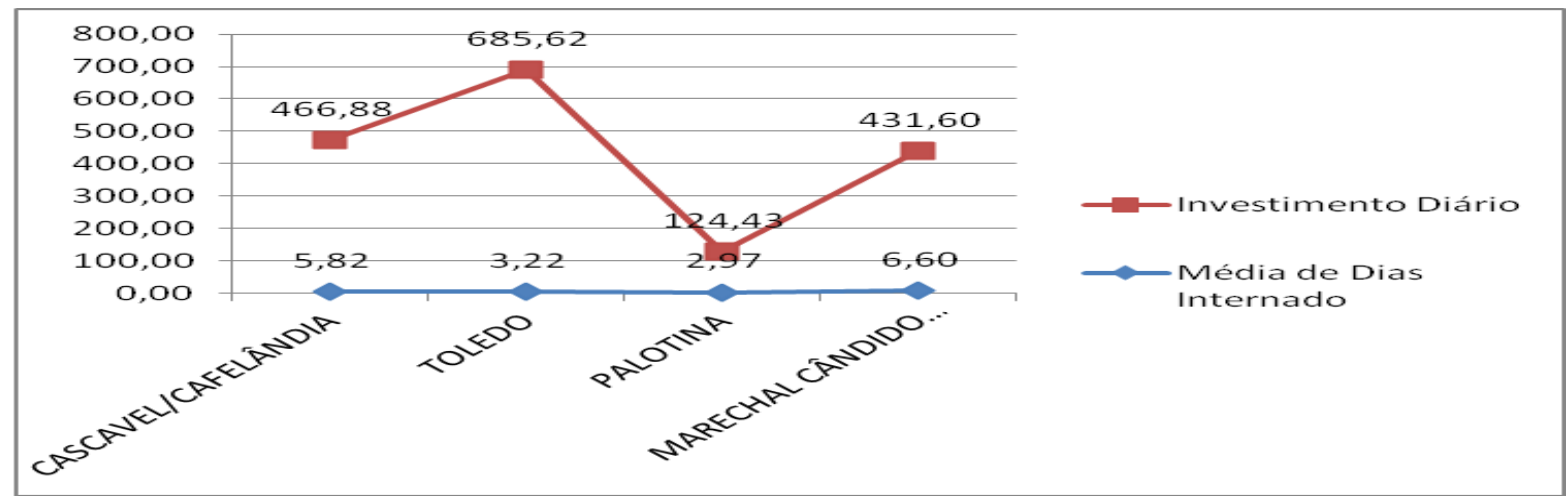

GRÁFICO 1 - DIAS DE INTERNAMENTO E INVESTIMENTO DIÁRIO COM JOVENS VÍTIMAS DE ACIDENTES DE TRÂNSITO

FONTE: Elaborado pelas autoras. Dados fornecidos pela SESA/PR (2016)

À primeira vista não é possível verificar se não há relação direta entre dias de internamento e valores, isso em função das quantidades e tipos de medicamentos utilizados. Mas, ainda assim, verifica-se que o maior custo diário dos internamentos ocorreu em Toledo, cujo dias de permanência foram similares aos de Palotina, que apresentou custo cinco vezes menor. Tal constatação sinaliza um fato interessante para aqueles que se dedicam aos estudos da gestão de recursos na política de saúde. Segundo os dados, Cascavel/Cafelândia registraram o maior tempo de permanência, contudo, foi a cidade de Toledo que apresentou o maior custo diário dos internamentos, fator que sugere a necessidade de um estudo mais aprofundado dessa evidência com vistas a esclarecer elementos diferenciais na composição desses números.

Dentre os principais limitadores para a análise dos custos em saúde está a questão dos planos de saúde. Os serviços de resgate obedecem ao protocolo nacional ${ }^{10}$ de entrada das vítimas via SUS, porém, quando possuem plano de saúde, seus familiares (ou a própria vítima) solicitam migrar para as formas de atendimento do plano, ainda que dentro da mesma instituição hospitalar. Todavia, convive-se com o fato de que, em muitos casos, em função das necessidades de coberturas, as vítimas atendidas pelos serviços do plano retornam ao SUS para a continuidade de tratamento iniciado.

Mediante uma observação preliminar e superficial dos dados das Regionais de Saúde $\left(10^{\mathrm{a}}\right.$ e $\left.20^{\mathrm{a}}\right)$, percebeu-se que são comuns as situações em que a vítima recebe o primeiro atendimento e, por diversos motivos, recebe alta da unidade hospitalar para, em seguida, retornar em uma nova

${ }^{10}$ Portaria Ministerial no 2.018, de 05 de novembro de 2002, e Portaria no 1.864 GM/MS, de 29 de setembro 2003. 
consulta e se for o caso, com nova $\mathrm{AIH}$, desvinculando-se esse atendimento do acidente ocorrido.

Sobre o tempo de permanência no hospital após o acidente de trânsito, Vieira (2015, p. 122) constatou em estudo realizado no Hospital da Faculdade de Medicina da Universidade de São Paulo, no período de julho de 2013 a julho de 2014, com pacientes em estado grave, que durante a internação hospitalar a quase totalidade das vítimas foi internada em UTI $(92,3 \%)$ e que o tempo médio de internação nessa unidade foi de 11,7 dias e a permanência hospitalar de 19,1 dias.

A autora reportou que 53,8\% dos pacientes internados em estado grave foram submetidos à cirurgia, 19,2\% tiveram reabordagem cirúrgica e que quadros infecciosos foram registrados em $25,6 \%$ dos casos. Outras complicações foram identificadas em 52,6\% dos pacientes, prolongando sua permanência e o custo de recuperação (VIEIRA, 2015, p. 122).

Ainda, segundo a mesma autora (2015, p. 124), do total do número de acidentados graves observados no período, 88,2\% alcançaram vida independente somente após seis meses do evento, sendo que outros $13,7 \%$ tiveram indicação de necessidade de ajuda humana ou dependência após a recuperação em UTI e, destes, 11,8\% ficaram dependentes no período dos seis meses de tratamento.

Oliveira e Sousa (2006, p. 286) realizaram estudo na cidade de Maringá - PR, cujo universo foi um grupo de 61 (sessenta e uma) vítimas de acidente de trânsito, condutores e garupas de motocicleta, que sofreram traumatismo crânio encefálico, os quais correspondiam a 21,9\% do número total de um determinado período. Com o estudo observaram que o tempo de internação nesse grupo variou de um a dez dias de internação.

Destaca-se no estudo de Oliveira e Sousa (2006) que 45,9\% das vítimas de motocicleta estavam desenvolvendo atividade remunerada no momento do acidente, 29,5\% em atividade de lazer e 24,6\% em outras atividades. Esse mesmo estudo apontou também que todas as vítimas de motocicletas retornaram à vida produtiva entre nove meses e um ano após o acidente e 20,4\% necessitaram de alteração na atividade produtiva.

Dados levantados por Sant ${ }^{\prime}$ Anna (2012, p. 93) demonstraram que o tempo de incapacidade estimado às vítimas e o consequente gasto do INSS em benefícios por estratos de valores apresentaram a frequência de 1,7\% relativo às incapacidades de até trinta dias. Os maiores percentuais foram entre 91 e 120 dias (33,2\%), 61 e 90 dias $(24,1 \%)$ e 121 e 180 dias (20,3\%). O autor coloca ainda que com relação aos gastos desses benefícios valores individuais mensais chegaram à ordem de até $\mathrm{R} \$ 1.107,52(87,6 \%)$ e indivíduos com valores maiores em benefícios entre $\mathrm{R} \$ 1.845,88$ e $\mathrm{R} \$$ $3.691,74(2,5 \%)$.

Os números expostos instigaram a simulação de uma situação hipotética, qual seja: a de um acidentado com duas lesões, que é a categoria predominante, que necessite de uma cirurgia, sem 
colocação de prótese ou órtese, e cuja vítima permaneça hospitalizada por seis dias (período máximo identificado e retratado no Gráfico 7), desconsiderando-se despesas de locomoção da família, medicamentos, fisioterapia, exames complementares e de acompanhamento. Apurou-se um custo estimado de cerca de $\mathrm{R} \$ 10.000,00$ (sendo $\mathrm{R} \$ 5.500,00$ valor estimado da cirurgia paga pelo SUS + 6 diárias do maior valor identificado nas regionais pesquisadas que é de $\mathrm{R} \$ 685,62)$. Considerando que o salário mínimo regional é de $\mathrm{R} \$ 953,47$, constata-se que o valor mínimo investido nesse único atendimento seria suficiente para bancar uma bolsa de estudo ou outra forma de qualificação para esse mesmo jovem para um período de dez meses e cinco dias.

Esse exercício de aproximação com a realidade cotidiana dos acidentes retratada por este estudo e por tantos outros como Gawryzewski, Mello-Jorge e Koizumi (2004) evidenciam que investir na formação, na qualificação e na especialização da força de trabalho jovem é uma ação que custa muito menos que o financiamento das intervenções em saúde, necessárias em decorrência dos acidentes de trânsito.

Acrescenta-se a essa questão o fato de que o trabalho manual realizado na agroindústria se dá na posição em pé do trabalhador, com o uso intenso das mãos e braços em movimentos repetitivos que consequentemente exige força de sustentação nos ombros. À medida que o maior lesionamento se dá nesses membros, ocorre o consequente comprometimento dessa mão de obra, visto que em muitos casos a extensão das lesões leva a limitações permanentes de alguns movimentos, retirando o sujeito definitivamente da competição por uma vaga nesse setor que é um dos mais importantes em empregos na região.

Outro aspecto a ser considerado são os óbitos ocorridos nos acidentes de trânsito, visto que o findar da vida de um jovem sempre será um evento imensurável do ponto de vista social e econômico, uma vez que se trata de um sujeito com muitas potencialidades produtivas, inventivas e criativas.

O maior número de óbitos em acidentes de trânsito acontece no local da ocorrência, em virtude da intensidade do impacto e da gravidade dos ferimentos ocasionados. O percentual de mortalidade pós-evento foi de 3,55\% na síntese das cidades pesquisadas. Dentre os números obtidos dois aspectos chamaram a atenção: o fato de Marechal Cândido Rondon não apresentar registro de óbito hospitalar, que estaria relacionado à transferência de paciente para o atendimento na cidade de Toledo; e o percentual de $8,33 \%$ de mortalidade registrado nos internamentos de Palotina em contraposição aos 3,07\% da cidade de Cascavel. Nesse caso, um dos fatores que pode ter interferido na contraposição desses números foi a disponibilidade de equipamentos e tecnologias para o suporte às vítimas de acidentes de trânsito. 
De maneira geral, a redução dos óbitos se associa a elementos como melhoria dos itens de segurança dos veículos, o aumento do uso de EPIs (Equipamentos de Proteção Individual), bem como a sinalização adequada e a conservação das vias.

A cidade de Toledo, por sua vez, conseguiu aumentar o número de pessoas que saíram ilesas no decorrer do triênio em $48 \%$. No entanto, está dada a seguinte contradição: ao mesmo tempo em que reduziu o número de feridos leves e graves, sem risco à vida, também aumentou o número de feridos graves com risco à vida e também de óbitos.

Os índices encontrados na cidade de Toledo sugerem a existência de condutas relacionadas à desobediência das leis de trânsito, ao aumento da velocidade e à alcoolemia, que aparece nos estudos de Santiago (2008); Gazal-Carvalho et al. (2002); Leyton et al. (2005).

De acordo com os registros, Marechal Cândido Rondon aumentou o número de pessoas que saíram ilesas em $48 \%$, bem como reduziu em 17,5\% as vítimas com ferimentos leves. Mas elevou o número de feridos graves, sem risco à vida, em $2,4 \%$ e o número de óbitos em $400 \%$, sugerindo ausência ou pouco investimento em mecanismos de controle e fiscalização da velocidade e do uso de equipamentos. Na direção de observar o número de lesões e sua letalidade, torna-se importante considerar a tipologia das ocorrências.

\section{Conclusões}

No campo das tensões da dinâmica produtiva, a cidade acaba por se constituir em palco para o acirramento das violências. Elegeu-se a do trânsito para ser abordada porque muitos tendem a naturalizar os acidentes de trânsito como um produto natural do desenvolvimento e, portanto, não merecendo a atenção diferenciada dos setores de segurança ou da saúde pública. Essa perspectiva se reflete, inclusive, no baixo número de estudos sobre os danos causados à sociedade e às pessoas em decorrência da violência no trânsito em cidades de pequeno e médio porte. Considera-se que as perdas de vidas e o comprometimento da capacidade laboral de pessoas jovens influenciam negativamente nas perspectivas de desenvolvimento de regiões inteiras.

No decorrer do estudo ficou demonstrado através de exercício aproximativo que o valores gastos com uma vítima de acidente fica na casa dos $\mathrm{R} \$ 10.000,00$, o que viabilizaria uma bolsa de estudo de dez meses para qualificar esse mesmo jovem.

Partindo dessa constatação, o estudo evidencia que se por um lado os gastos financeiros podem ser mensurados, de outro lado os impactos sociais que dizem respeito ao círculo familiar, 
amigos, empresa e sociedade tornam-se intangíveis na mesma proporção em que o número de lesões, sua extensão e gravidade se ampliam, a ponto de comprometer a vida da vítima e de outras pessoas da família, até porque para muitos o afastamento do trabalho temporário ou permanente pode levar ao consequente empobrecimento.

Pode-se destacar o estabelecimento da compreensão por parte da gestão pública, e da população em geral, de que acidentes de trânsito são problemas de saúde pública e passam de uma ação setorial para uma ação coordenada em rede.

Urge pensar as cidades para as pessoas, de modo a promover a reorganização física do espaço ocupado pelo trânsito, garantindo a circulação segura de pedestres e ciclistas.

Tomando as cidades estudadas, ficou evidenciado que Cascavel vem investindo há anos nos três eixos interventivos e apresenta hoje os melhores resultados. Entretanto, as cidades menores, que somente agora estão dando os primeiros passos para a implantação de uma política de trânsito, veem o crescimento dos números de ocorrências nos últimos anos.

Além de garantir o tripé educação/fiscalização-punição/infraestrutura, há que existir a preocupação com a garantia de recursos humanos e financeiros para a execução contínua dessas ações.

Apesar dos portes médio e pequeno, as cidades pesquisadas não deixaram de reproduzir, em seus números, as tendências registradas em cidades grandes, como por exemplo, o crescimento da motorização privada em detrimento da pública. O Estado brasileiro passou a incentivar o uso da motocicleta como solução para as questões mercadológicas, de mobilidade e de geração de renda para os jovens que não eram absorvidos pelo trabalho formal, em linhas tradicionais das fábricas, ou seja, os mais pobres e de menor escolaridade.

Esse modelo se associa à perspectiva de um crescimento que se dá a qualquer custo, ignorando seus impactos negativos, inclusive aqueles alusivos às perdas de vidas de todas as idades, especialmente as de jovens. Essas perdas passaram a ser vistas como inerentes ao processo de desenvolvimento como algo inevitável, ou seja, o preço a ser pago pelo aumento da frota e dos fluxos.

Como sinaliza CEPAL (2013): caso os países da América Latina e, especificamente, o Brasil não se atentem para essa perspectiva equivocada de tratar as mortes prematuras, estará se perdendo um dos momentos mais propícios para a transição econômica e para o desenvolvimento do país. Segundo esse documento, os países latino-americanos vivem, nesse momento, sob a égide dos benefícios do chamado "bônus demográfico", caracterizado pelo aumento de pessoas em idade produtiva. Esse bônus se produziu a partir das conquistas do controle das doenças infecto-contagiosas e da redução da mortalidade infantil. Também alerta para a necessidade de ações de proteção à vida 
de pessoas mais jovens como estratégia de desenvolvimento, chamando atenção para o fato de que caso isso não ocorra, ainda nesta década, poderá ser tarde, ficando reservado às futuras gerações o ônus de uma pobreza ainda mais acentuada que aquela vivida até então.

Este estudo não esgota a temática dos acidentes de trânsito nas cidades investigadas, mas sinaliza possibilidades para outras investigações que possam, inclusive, dar uma dimensão mais humana aos dramas que circunscrevem a questão do comprometimento da força de trabalho dos jovens e do consequente empobrecimento não só da pessoa lesionada como da sua família e, consequentemente, das cidades.

Assim, há que se considerar que a prevenção dos acidentes de trânsito, diz respeito acima de tudo a estratégia de criação de cidades mais saudáveis, capazes de superar o paradigma do conceito equivocado de que desenvolvimento é sinônimo de crescimento econômico, pois na verdade o desenvolvimento territorial sustentável é muito mais amplo e multidimensional, devendo articular-se a partir da perspectiva de que pessoas mais saudáveis são mais ativas, mais criativas e mais propositivas, logo mais aptas a promover o desenvolvimento em suas múltiplas dimensões.

\section{Referências}

GAWRYZEWSKI, V. P.; MELLO, J. M. H. P., KOIZUMI, M. S. Mortes e internações dos idosos no Brasil: o desafio de integrar a saúde coletiva e a atenção individual. Ver. Assoc. Med. Bras, v. 50, n. 1, p. 97-103, 2004.

GAZAL-CARVALHO, C. et al. Prevalência de alcoolemia em vítimas de causas externas admitidas em centro urbano de atenção ao trauma. Revista de Saúde Pública, São Paulo, v. 36, n. 1, p. 1-13, fev. 2002.

INSTITUTO DE PESQUISA ECONÔMICA APLICADA (IPEA); DEPARTAMENTO NACIONAL DE TRÂNSITO (DENATRAN); ASSOCIAÇÃO NACIONAL DE TRANSPORTES PÚBLICOS (ANTP). Impactos sociais e econômicos dos acidentes de trânsito nas rodovias brasileiras. Relatório Executivo. Brasília, 2006.

INSTITUTO DE PESQUISA ECONÔMICA APLICADA (IPEA). Acidentes de trânsito nas rodovias federais brasileiras: caracterização, tendência e custos para a sociedade. Relatório de Pesquisa. Brasília, 2015.

LEYTON, V. et al. Perfil epidemiológico das vítimas fatais por acidente de trânsito e a relação com o uso de álcool. Saúde, Ética \& Justiça, v. 10, n. 1-2, p. 12-18, 2005. 
MELiOne, L. P. R.; MELlo-JORGE, M. H. P. de. Gastos do Sistema Único de Saúde com internações por causas externas em São José dos Campos, São Paulo, Brasil. Cad. Saúde Pública, Rio de Janeiro, v. 24, n. 8, p. 1814-1824, ago. 2008.

MESQUITA FILHO, M. Acidentes de trânsito: as consequências visíveis e invisíveis à saúde da população. Revista Espaço Acadêmico, n. 128, jan. 2012.

OLIVEIRA, N. L. B. de; SOUSA, R. M. C. de. Diagnóstico de lesões e qualidade de vida de motociclistas, vítimas de acidentes de trânsito. Rev. Latino-Am. Enfermagem, Ribeirão Preto, v. 11, n. 6, p. 749-756, dez. 2003. Disponível em: <https://goo.gl/fjf6xm>. Acesso em: 25 ago. 2016.

SANT'ANNA, F. H. M. Características das vítimas de acidentes de transporte terrestre, lesões e benefícios concedidos entre segurados do Instituto Nacional do Seguro Social de Cambé (PR) em 2011. Dissertação de Mestrado do Programa de Pós-Graduação em Saúde Coletiva. Londrina, 2012.

SANTIAGO, E. de F. Alcoolemia em vítimas fatais de acidentes de trânsito no Rio Grande do Norte empregando cromatografia em fase gasosa - Head space. Dissertação de Mestrado. Universidade do Rio Grande do Norte. Natal, 2008.

VIEIRA, R. de C. A. Recuperação das vítimas de lesão axonial difusa e fatores associados. Tese de Doutorado. Escola de Enfermagem da Universidade de São Paulo. São Paulo, 2015.

Artigo recebido em 14/11/2017. Aceito para publicação em 18/12/2017. 